\title{
"TEM QUE ESTAR BONITO PRA VENDER": A PRODUÇÃO SENEGALESA DE ESPAÇOS DE VENDA EM SANTA MARIA (RIO GRANDE DO SUL, BRASIL)
}

\author{
"You have to look beautiful to sell": the Senegalese production of trade \\ spaces in Santa Maria (Rio Grande do Sul, Brazil)
}

\author{
Filipe Seefeldt de Césaro* \\ Maria Catarina Chitolina Zanini**
}

\begin{abstract}
Resumo. Este artigo trata da venda de rua senegalesa na cidade de Santa Maria (Rio Grande do Sul, Brasil), procurando responder à seguinte questão: "como a produção de espaços de venda pelos senegaleses de Santa Maria contribui para a sua inserção no comércio de rua da cidade?". Por meio de uma etnografia desenvolvida entre 2016 e 2017, propomos que a produção de espaços de venda por esses imigrantes constitui de uma prática cotidiana que os representa positivamente nas interações com a clientela e os diferencia etnicamente de outros vendedores de rua que ocupam o mesmo espaço social.
\end{abstract}

Palavras-chave: migração senegalesa; venda de rua; espaço.

\begin{abstract}
This paper deals with the Senegalese street sales in the city of Santa Maria (Rio Grande do Sul, Brazil), seeking to answer the following question: "how does the production of sale spaces by the Senegalese people, in Santa Maria, contributes to their insertion in the city's street commerce?" Through an ethnography developed between 2016 and 2017, we propose that the production of sales spaces by these immigrants constitutes a daily practice that positively represents them in the interactions with the clientele and ethnically differentiates them from other street vendors who occupy the same social space.
\end{abstract}

Keywords: Senegalese migration; street sale; space.

\section{Introdução}

Este trabalho é constituído por parte das proposições analíticas elaboradas em uma etnografia intitulada “'Tem que conversar, senão não vende, né?': a

\footnotetext{
* Universidade Federal de Santa Maria (UFSM). Santa Maria, RS, Brasil.

** Professora associada da Universidade Federal de Santa Maria (UFSM). Santa Maria, RS, Brasil.
} 
inserção de imigrantes senegaleses no comércio de rua de Santa Maria (RS)"1. A pesquisa original indagou sobre os modos de inserção cotidianamente vividos por seis senegaleses no comércio informal da cidade de Santa Maria (Rio Grande do Sul, Brasil). Nesse sentido, entre agosto de 2016 e dezembro de 2017, um dos autores do presente artigo acompanhou os vendedores de rua senegaleses da cidade durante seu dia a dia laboral. Compartilhando o trabalho analítico, ambos procuramos descrever suas técnicas de venda e as sociabilidades nas quais se envolviam como táticas de inserção no comércio de rua santa-mariense. Em tal tarefa, partimos da abordagem metodológica desenvolvida por Clifford Geertz $^{2}$, que propõe que o exercício etnográfico constitui de uma interpretação de interpretações: entre campo e escritório, o pesquisador se esforça por aperfeiçoar a própria leitura do texto parcialmente ilegível representado por seu objeto de investigação. Na observação participante ${ }^{3}$ realizada junto aos senegaleses de Santa Maria, no diário de campo mantido e na produção do texto analítico, mantivemo-nos conscientes da parcialidade de nossas interpretações, enquanto leituras negociadas e aperfeiçoadas na experiência intersubjetiva desenvolvida com os interlocutores por um dos autores. Antes de partir ao foco do presente artigo, é necessária breve nota contextual.

As forças propulsoras da migração internacional senegalesa estão relacionadas a uma série de fatores complexos dos quais apenas uma pequena parte podemos referenciar, brevemente, aqui. Vale partir da gradual e inesperada chegada de senegaleses à Argentina durante os anos $1990^{4}$ e ao Brasil durante os anos $2010^{5}$. Tomando por referência as rotas já comumente

1 Produzida no formato de pesquisa de Mestrado, vinculada ao Programa de Pós-Graduação em Ciências Sociais da Universidade Federal de Santa Maria (UFSM) e ao NECON (Núcleo de Estudos Contemporâneos da UFSM, coordenado pela professora Maria Catarina Chitolina Zanini). O trabalho é resultado da relação de orientação e de reflexões conjuntas desenvolvidas pelos dois autores do presente artigo desde o início da pesquisa. Enquanto ambos realizaram conjuntamente a análise, a investigação empírica foi desenvolvida por somente um dos autores, tendo o outro o papel de orientação e revisão durante todo o período de pesquisa.

2 GEERTZ, Clifford. A interpretação das culturas.

3 A aproximação em relação aos interlocutores se deu, primeiramente, sem a pretensão da pesquisa. Após a primeira aproximação, em meados de 2015, por meio de rápidas conversas informais nas calçadas onde os senegaleses realizavam sua venda, um dos autores passou a participar, ao final de 2016, de algumas das aulas de português fornecidas ao grupo de imigrantes por membros do MIGRAIDH (Grupo de Pesquisa, Ensino e Extensão Mobilidade Humana e Direitos Humanos, e Cátedra Sérvio Vieira de Mello UFSM). Esforçando-se por contribuir com o aprendizado da língua portuguesa por esses imigrantes, foi possível a um dos autores desenvolver uma relação de confiança com os senegaleses. Ao longo de algumas das aulas, este apresentou-lhes a proposta de pesquisa de Mestrado e, gradualmente, passou a acompanhá-los em seus expedientes de trabalho nas calçadas, observando e participando das interações face a face nas quais se envolviam no cotidiano.

4 ZUBRZYCKI, Bernarda. Senegaleses en Argentina: un análisis de la Mouridyya y sus asociaciones religiosas. Boletín Antropológico, v. 1, n. 81, 2011, p. 49-64.

5 DE CÉSARO, Filipe, BARBOSA, Lorena Salete, ZANINI, Maria Catarina. Um panorama das migrações internacionais para o sul do Brasil: haitianos e senegaleses em movimento. 
utilizadas pela imigração haitiana, os senegaleses majoritariamente passaram a desembarcar em Quito (Equador) para, em seguida, ingressar no estado do Acre, partindo do Peru (via Rodovia Interoceânica), opção que não Ihes demanda nenhum visto durante o caminho todo ${ }^{6}$. Foi esta a trajetória de entrada no Brasil utilizada pelos interlocutores desta pesquisa, atraídos a Santa Maria pelas informações de compatriotas acerca das possibilidades de emprego na cidade ${ }^{7}$. Após trabalharem um tempo em uma obra de construção civil, decidiram se dedicar ao comércio de rua, tal qual grande parte dos senegaleses estabelecidos no estado e no país. Isso porque, na construção civil, os salários não eram suficientes para o envio de remessas à família no Senegal e o tratamento recebido por alguns dos colegas de trabalho era considerado inadequado ${ }^{8}$. O grupo de Santa Maria, com esse movimento de mudança de área profissional, inseriu-se num espaço social marcado por relações de poder historicamente consolidadas entre vendedores de rua, lojistas, poder público e imprensa ${ }^{9}$. De acordo com as conjunturas de articulação política entre esses atores, o comércio de rua na cidade assumia condições de possibilidade variáveis, as quais os senegaleses recém-chegados tenderiam, com o tempo, a interpretar e enfrentar de seu próprio modo.

Tendo esse quadro geral em vista, pretendemos aqui focar em uma questão específica que fez parte da pesquisa introduzida há pouco: a produção de espaços empregada pelos senegaleses de Santa Maria para configurar seus pontos de venda na cidade. Para tal, partimos dos dados empíricos aos quais um dos autores teve acesso por meio de pesquisa etnográfica entre/ com senegaleses em sua rotina laboral. Por conta da adequação aos limites do presente formato textual, apenas quatro dos seis interlocutores aparecem nos dados empíricos referenciados a partir do diário de campo produzido. Ahmadou $^{10}$ (23 anos), Maba (27 anos) e Cheikh (25 anos) chegaram a Santa

6 HERÉDIA, Vânia et alii. Migrações Internacionais: o caso dos senegaleses no sul do Brasil. Caxias do Sul: Belas-Letras, 2015.

7 Dos seis senegaleses com os quais um dos autores teve contato para a pesquisa, apenas um teve sua solicitação de refúgio aceita após, por anos, esperar ver seu nome nas listas do Conselho Nacional para Refugiados. Chegados a Santa Maria entre 2014 e 2016, esses seis imigrantes procuraram a regularização pelo refúgio, medida que ainda hoje é a mais utilizada, mesmo com a aprovação (com uma série de vetos) da nova Lei da Migração em 2017.

8 MOCELLIN, Maria Clara. Deslocamentos e trabalho ambulante entre jovens senegaleses no Rio Grande do Sul. In TEDESCO, João Carlos, KLEIDERMACHER, Gisele (orgs.). A imigração senegalesa no Brasil e na Argentina: múltiplos olhares, p. 339-359.

9 PINTO, Matheus Rosa. As metamorfoses do trabalho urbano: o caso dos comerciantes informais de Santa Maria - RS (1980-2011). [Dissertação de Mestrado em História] Universidade Federal de Santa Maria, 2015.

${ }^{10}$ Os interlocutores desta pesquisa são referenciados aqui por nomes fictícios em função, especialmente, da vulnerabilidade do grupo na cidade, considerando-se a frequência com que são alvo das violentas apreensões da fiscalização municipal. Pela mesma razão, a identidade dos interlocutores também é preservada nas fotografias utilizadas mais à frente. 
Maria em 2016, enquanto Maodo (33 anos) o fez em 2014. Todos partiram de uma pequena cidade chamada Notto Gouye Diame, no Senegal, onde eram agricultores que, periodicamente, viajavam a Thiès para trabalhar com a venda de rua. Sem acesso à educação superior, chegaram ao comércio informal de Santa Maria apostando em melhores condições de vida para si e para suas famílias. Tendo isso em vista, nas páginas a seguir, procuramos responder à seguinte questão: "como a produção de espaços de venda pelos senegaleses de Santa Maria contribui para sua inserção no comércio de rua da cidade?".

\section{De imigrantes a vendedores de rua de Santa Maria: o} aprendizado de espaços comerciais

Para além das especificidades de cada contexto, o migrante internacional é confrontado com um abismo entre dois mundos simbólicos diferentes. Onde quer que vá e seja lá o que fizer, seu cotidiano tenderá a envolver um aprendizado constante marcado pelo esforço em interpretar os significados que têm eficácia social nos ambientes interacionais nos quais busca inserção ${ }^{11}$. Em Santa Maria, percebeu-se, ao longo do trabalho de campo, que as expressões corporais dos senegaleses nas interações que mantinham no espaço social do comércio informal da cidade eram uma dimensão importante de como viviam essa condição migratória. Ao inventarem modos regulares de comportamento corporal frente aos clientes, esses imigrantes buscavam estabelecer um "consenso funcional"12 nas interações que mais importavam em seu ofício: um senso de normalidade implicitamente compartilhado entre esses vendedores e os clientes e que possibilita a estabilidade das relações de compra e venda. É uma adequação criativa do "eu" interacional por parte dos senegaleses chegados ao comércio de rua santa-mariense, expressa em como os objetos, o corpo e a linguagem são dispostos. Assim, o trabalho de campo revelou que, ao invés de um conhecimento "pronto", trata-se de uma construção constante: em cada interação em que os senegaleses engajavam-se, havia sempre uma "margem de erro" capaz de levar ao constrangimento, ao desconforto ou, mesmo, ao conflito ${ }^{13}$. Ao mesmo tempo seguros de si e expostos ao erro, esses novos vendedores de rua de Santa Maria aprendiam no improviso de cada experiência social ${ }^{14}$.

Esse modo de existência ao qual o migrante internacional está submetido é tratado por Abdelmalek Sayad ${ }^{15}$ como o palco de uma luta identitária. Isso significa dizer que, ao fundo dos usos instrumentais que o migrante faz daquilo

11 GEERTZ, op. cit.

${ }^{12}$ GOFFMAN, Erving. A representação do eu na vida cotidiana, p. 218.

${ }^{13}$ DE CÉSARO, Filipe, ZANINI, Maria Catarina. Migração senegalesa e mouridismo: um breve exercício interpretativo, p. 261.

${ }^{14}$ INGOLD, Tim. Da transmissão de representações à educação da atenção. Educação, v. 33, n. 1, 2010, p. 6-25.

${ }^{15}$ SAYAD, Abdelmalek. A imigração ou os paradoxos da alteridade, p. 46, 61, 64. 
que aprende em seu cotidiano, há um processo violento de reimaginação de si. O indivíduo é envolvido, assim, pelo fenômeno do transnacionalismo que, potencializado pelo avanço contemporâneo das tecnologias da informação e da comunicação, constitui uma transformação identitária vivida no interior de redes sociais que ligam a origem e o destino ${ }^{16}$. Entre interações aqui e lá, o migrante assume, abandona e conjuga diferentes papeis sociais, avaliando seu empreendimento migratório pelas experiências de quem ficou, de quem foi para outros países e de quem passa a conhecer na nova morada ${ }^{17}$. No caso dos senegaleses de Santa Maria, facilmente identificados como imigrantes pelas marcas da cor de pele ${ }^{18}$ e do domínio da língua, isso se traduz na preocupação (que comumente se percebeu em campo) em saber o que fazer, como fazer e quando fazer nas interações face a face. São desafios diários que, em termos de aprendizado social, põem à prova os laços mantidos com a nação de origem ${ }^{19}$. Em meio a tantos estranhamentos, o imigrante sente que deve, emergencialmente, aprender e negociar significados socialmente. "Se um cara bebe muito, aqui, tu pode deixar ele, não precisa falar", dizia Maba certa vez, relatando reconhecer o fato de que, a seu ver, no Brasil, não é necessário repreender alguém que está fazendo algo errado, ao contrário do que acontece no Senegal (Diário de campo, 28/06/2017). No que toca ao foco desta reflexão, vale relembrar Marcel Mauss ${ }^{20}$, para destacar que a corporalidade constitui "claramente de um ensino técnico, e que há, como para toda técnica, uma aprendizagem". Nesse sentido, como relembra Le Breton, assumir novas identidades sociais é também assumir papeis corporais correspondentes ${ }^{21}$ : é o caminho seguido pelo migrante que busca inserção nos contextos de seu destino. O dilema identitário do "estar aqui/estar lá", assim, tem uma dimensão corporal que se mostra prática nas interações cotidianas do migrante na sociedade de recebimento.

Em Santa Maria, as observações de campo demonstraram a relevância de como os senegaleses "montavam" fisicamente seus pontos de venda. Mais especificamente, atentamos para dois elementos desse processo: a vestimenta do vendedor e a configuração dos produtos expostos. Ao contrário de elementos aleatórios, percebeu-se, em ambos, uma lógica material repetida dia após dia: tratava-se de um espaço pensado, do início ao fim do expediente, como um

\footnotetext{
${ }_{16}$ VERTOVEC, Steven. Transnationalism, p. 82, 146.

17 GLICK-SCHILLER, Nina, LEVITT, Peggy. Conceptualizing simultaneity: a transnational social field perspective on society.

18 As relações raciais e sua ingerência sobre parte das interações entre senegaleses e clientes em Santa Maria são temas trabalhados em outras partes da análise desenvolvida na pesquisa original, não figurando, aqui, por conta do recorte analítico selecionado.

${ }^{19}$ FOURON, Georges, GLICK-SCHILLER, Nina. Laços de sangue: os fundamentos raciais do Estado-nação transnacional, p. 49.

20 MAUSS, Marcel. Sociologia e antropologia, p. 402.

${ }^{21}$ LE BRETON, David. A sociologia do corpo, p. 9.
} 
dispositivo urbano distinguível no interior do espaço comercial da cidade. Como demonstra Erving Goffman ${ }^{22}$, as configurações físicas não são apenas um pano de fundo desconectado das interações correntes, mas um dado de ingerência sobre elas. Nessa esteira goffmaniana, a categoria de "fachada pessoal" chama a atenção. Trata do conjunto de equipamentos performáticos expressos no corpo do ator em dado espaço social: são materiais "portáteis". Assim, propomos que a persona social dos vendedores senegaleses em Santa Maria inclui uma fachada que os define corporalmente: as vestes e acessórios, a maleta de bijuterias, as grandes mochilas preenchidas por roupas, tênis e pequenos eletrônicos, bem como a caixa de papelão usada para apoiar os produtos, estão dentre os materiais principais. São elementos de um espaço montado para a interação comercial, ou seja, previsto pelos senegaleses como o palco ideal para a performance que realizarão ${ }^{23}$.

Uma tarefa paisagística, então, constitui parte dos esforços dos senegaleses em sua rotina de trabalho em Santa Maria. Entre as 8 e 9 horas, apressam-se por algumas das calçadas. Buscam chegar ao centro, onde um calçadão, uma praça e uma porção de ruas paralelas servem de palco ao variado comércio de rua da cidade. Depois de, aproximadamente, 10 minutos, chegam ao destino escolhido para a montagem do ponto de venda. Na mochila comumente usada, uma das duas possibilidades de produtos é transportada. A primeira delas é a característica maleta prata cheia em bijuterias. Quando aberta sobre uma caixa de papelão (que na caminhada é carregada em uma das mãos), revela-se com um estofado vermelho que, em divisórias e penduricalhos, guarda os produtos dourados em uma posição diagonal facilmente identificável. É comum que, ao lado da maleta, no espaço da caixa que sobra, alguns pares de meias sejam também expostos (no caso do inverno), ou, ainda, certa quantia de eletrônicos (pen drives, caixas de som portáteis e fidget spinners, por exemplo). Na metade superior do interior da maleta, encontram-se correntes e pulseiras, enquanto a metade inferior é ocupada por anéis (fixados em buracos feitos em uma pequena prancha de isopor e plástico) e relógios (vestidos em volta de cilindros feitos do mesmo material). A segunda possibilidade de produtos que a mochila carrega é, nos relatos dos senegaleses, marcadamente menos segura no que toca às apreensões dos fiscais: caso seja necessário fugir, é de carregamento mais difícil. Trata-se de uma lona, normalmente azul, que é

${ }^{22}$ GOFFMAN, op. cit., p. 29-34.

${ }^{23}$ Elementos específicos dessa performance observada em campo, como a linguagem e os gestos, não são aprofundados no presente artigo por não fazerem parte do enfoque analítico pretendido. Ainda assim, vale destacar a pertinência, na pesquisa original, da categoria de "performance como espetáculo" proposta por Luciana Hartmann para descrever um tipo teatral de performance que observa em contadores de "causos" da fronteira entre Argentina, Brasil e Uruguai. Cf. HARTMANN, Luciana. Performance e experiência nas narrativas orais da fronteira entre Argentina, Brasil e Uruguai, p. 135. 
estendida no chão, sobre a qual é exposta grande quantia de peças de vestuário uniformemente dobradas. Aqui, as mochilas levam a lona e um número extra de produtos, já que é em uma das mãos que a maior parte dos produtos é carregada. Roupas e calçados de diferentes modelos, cores e tamanhos são organizados em duas seções de venda: mais acima, as peças para adultos são dispostas na ordem de suas características, enquanto, mais abaixo, estão as peças infantis em organização similar. Apesar disso resultar em um ponto de venda consideravelmente maior do que o das bijuterias, o formato dado à lona deixa pouca margem de sobra em relação à área ocupada pelas roupas: tal cuidado evita que o espaço produzido invada demasiadamente a parte central das calçadas, onde o fluxo de pedestres é mais intenso.

$\mathrm{O}$ almoço ocorre em casa ou em algum dos restaurantes centrais com preço acessível: entre as 12 e 13 horas, os senegaleses se revezam na pausa, desmontando e montando seus pontos de venda novamente. Um dia de trabalho normal para esses senegaleses costuma terminar apenas quando o fluxo de transeuntes enfraquece ao fim do dia. Até esse momento, mantêm uma gestão do espaço produzido, rearranjando imediatamente quaisquer produtos desarrumados pelo vento ou pelas mãos interessadas dos clientes. Segundo as observações de campo, foram raras as vezes em que o cenário da venda permaneceu, de alguma forma, desajustado por mais de poucos minutos.

É por meio desse procedimento cotidiano que os senegaleses de Santa Maria constroem espaços de comércio informal que, dentro de suas limitações, são pensados para serem atrativos: ao menos, captam facilmente o olhar de quem passa na calçada. Nesse sentido, cenários como os dos pontos de venda senegaleses de Santa Maria são produções espaciais com intenção simbólica definida, isto é, interpretam o que faz sentido ao observador naquela situação e se esforçam por emular criativamente tal significado. Mas qual a referência dos senegaleses em questão para essa adequação criativa? Sobre tal pergunta, vale atentar para a dimensão relacional dessas produções espaciais dos senegaleses de Santa Maria.

\section{Entre criação e adequação: produzindo espaços para clientes e entre vendedores}

Vendedores de amendoim, abacaxi, morango e lanches, artesãos hippies ${ }^{24}$, artesãos indígenas, vendedores de filmes e jogos eletrônicos, de guarda-chuvas, de toalhas de cozinha, de balóes infantis, de perfumes, pulseiras, máquinas de costura, doces, agulhas e raladores. Tal variedade de trabalhadores de rua representa apenas uma parte dos grupos que, durante a investigação empírica,

\footnotetext{
${ }^{24}$ Termo popularmente utilizado em Santa Maria para denominar os artesãos vendedores de rua que, em sua atuação na cidade, tomam por referência identitária os hippies e sua produção contracultural na década de 1960.
} 
conviviam de diferentes formas com os senegaleses na região central de Santa Maria. Isso significa que, em campo, era comum que a atenção seguisse os caminhos fornecidos pela paisagem comercial variada: era inevitável que o autor lá presente se impressionasse com as diferentes formas de produção de espaços de venda e, em especial, indagasse suas razões simbólicas.

Os ocupados com a exposição de artesanato estavam comumente sentados no chão ou em confortáveis cadeiras, atentos na fabricação, "em tempo real", de novos produtos. As mãos manchadas no espaço aberto entre as pernas manejavam as ferramentas necessárias para cada empreendimento artístico. Entre arames, pedras, tintas, latas e fios de linhas, os artesãos constroem um espaço que remete quem o observa à proximidade entretida entre produtos e produtor. "A pedra desse colar é uma ágata, dá determinação, autoconfiança..." foi o conselho de uma artesã hippie ao autor em campo, sobre um dos produtos observados. Fabricar novas peças ao mesmo tempo em que se dá o atendimento de clientes não só serve à necessidade de reposição de produtos, mas também à de comprovação da autenticidade da arte, do artista e da relação entre ambos. Nos casos representativos dos artesãos hippies e dos indígenas, é especificamente a relação com a terra que se objetiva evidenciar. Pés descalços, vestes rendadas, leves e coloridas, complementadas por dreadlocks ${ }^{25}$ nos cabelos (no caso hippie) e por acessórios feitos de penas, tintas e plantas (no caso indígena), formam pontos de venda cuja pretensão principal é a da naturalidade que resulta em autenticidade: feitos à mão e vendidos por preços estipulados para garantir apenas a subsistência dos artesãos, os produtos são uma extensão do estilo de vida dos vendedores. A pretensão é a de que a atividade comercial ali realizada se afasta das cópias e da acumulação existentes em outros espaços de venda. "Tá quentinho", repetia, nesse mesmo sentido, um vendedor de lanches que, comumente, aparecia nas experiências de campo.

Por outro lado, há grupos de vendedores cujos espaços de trabalho contêm, em si, uma intenção simbólica diferente. A venda de rua senegalesa está aqui situada, ao lado dos vendedores que se ocupam com DVDs, toalhas de cozinha e caixas de morangos, por exemplo. O relacionamento que esses vendedores espacialmente mantêm com seus produtos é de afastamento. Ao invés de próximos ao chão, permanecem em pé, atrás de sua exposição e em uma postura ereta: com os olhos revezando entre os produtos e os clientes, apenas manipulam o que expõem para ajustar sua organização, alcançar o produto a algum comprador interessado ou, ainda, a alguém que exige a troca de algo defeituoso. Trata-se, assim, de um cenário em que o comerciante se representa, exclusivamente, como revendedor dos produtos expostos e não como o artista que os criou. É justamente por conta desse afastamento,

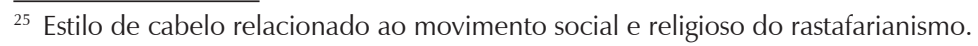


de quem apenas repassa os itens e não se responsabiliza pela qualidade dos mesmos, que tais vendedores exaltam uma capacidade de fornecer ao cliente um julgamento isento sobre o que vendem. Assim, não destacam uma propriedade artesanal de seus produtos, mas a sua qualidade atestada pelo fato de terem comprado para revendê-los. "Os DVDs que eu vendo eu garanto que são bons...", "o morango aqui é novinho!" e "essa pulseira aqui não descasca, e tu pode usar ela todo o dia, na rua e em casa, em todo lugar..." foram frases recorrentes no trabalho de campo e que tornam explícito o sentido dado a espaços concebidos como de profissionais, e não de artistas.

Tendo tudo isso em vista, podemos pressupor que a produção de espaços de venda pelos senegaleses em Santa Maria é relacional, pois está envolta por grupos cujos espaços comerciais contêm intenções simbólicas diferenciadas. É tal circunstância social que possibilita uma adequação e, paralelamente, uma apropriação dos senegaleses em relação "àquilo que já estava sendo feito" quando da sua chegada. Ficam ao lado de um tipo de produção espacial comum entre dado número de vendedores de rua enquanto, ao mesmo tempo, geram pontos de venda autênticos em seus elementos estruturais já descritos. Aos transeuntes que por ali passam, torna-se, assim, "razoável" e "normal" se aproximar de um senegalês parado na calçada, já que a cena é chamativa sem ser completamente estranha, ou seja, é original, mas não a ponto de destoar completamente dos espaços de outros vendedores.

Essa concepção social do espaço da venda senegalesa em Santa Maria, por sua vez, consolida-se na forma de um "fazer" cotidiano. Isso porque as práticas desses vendedores para a montagem de seus pontos de venda possuem um caráter político autodissimulado: repetidas diariamente, apresentam-se ao pesquisador e aos atores envolvidos no mesmo espaço social como detalhes insignificantes de um ofício. Ao longo das observações de campo, percebeu-se que era justamente esse teor sub-reptício do estender a lona no chão, do abrir a maleta sobre o papelão e do dispor os produtos em dada ordem que dava um sentido político eficaz aos pontos de venda senegaleses na cidade. Ao montarem e desmontarem os cenários de seu ofício, os imigrantes ressignificam a calçada, que, em termos de política pública, é idealizada como pista de passagem, onde as inércias são sempre limitadas aos olhares fixados nas vitrines das lojas e o movimento é desobstruído a quem vai e volta do trabalho ${ }^{26}$. Em reportagem do Diário de Santa Maria (publicada em setembro de 2017), um dos principais periódicos da imprensa local, o prefeito municipal Jorge Pozzobom opinou nesses

\footnotetext{
${ }^{26}$ A venda de rua senegalesa em Santa Maria é irregular e alvo constante das apreensões operadas pela Superintendência de Fiscalização, órgão da Prefeitura Municipal responsável por implementar a legislação nas calçadas da cidade. Cf. SANTA MARIA, lei complementar 92, 2012, art. 12 § 1‥ Disponível em: < http://www.camara-sm.rs.gov.br/camara/proposicao/pesqui salegislacao/2018/2/0\#lista_texto_proposicao>.
} 
termos sobre o comércio de rua: "Vamos tratar essas questões com regramento. Não é crível, não é aceitável que algumas pessoas paguem suas taxas e alvarás, e outras vão para rua sem vigilância, sem fiscalização. O Centro é de todos, não podemos permitir essa esculhambação. Vamos enfrentar tudo. Até o final do ano, estaremos com tudo delimitado, e a bagunça que está no Centro, não terá mais". Era como se reverberasse o mesmo discurso repetido há décadas na cidade: "o ideal seria uma cidade sem ambulantes", apostava, em 1991, o diretor geral da Secretaria de Indústria, Comércio e Turismo de Santa Maria ${ }^{27}$.

Por meio de práticas espaciais pouco visíveis a essa alta política que os ilegaliza, mas cujo resultado é atrativo à clientela, os senegaleses procuram deixar sua marca imagética no comércio de rua da cidade ${ }^{28}$. A noção de "fazer" de Michel de Certeau torna-se útil, aqui, por tratar de agências de caráter furtivo que, imbricadas com as operações rítmicas de um cotidiano, apropriam-se discretamente do sistema de produção que procura dominá-las. No presente caso, trata-se de práticas de manipulação do espaço que transformam as calçadas, planejadas pela administração pública como lugares exclusivamente de passagem, em pontos de venda atrativos. Dessa forma, o fazer de espaços dos senegaleses de Santa Maria é "disperso, mas insinua a si mesmo em todo o lugar, silenciosamente e quase invisivelmente, porque não se manifesta por meio de seus próprios produtos, mas ao invés disso pelos modos de usar os produtos impostos por uma ordem econômica dominante"29. Propomos, então, que as práticas cotidianas já descritas e por meio das quais esses imigrantes produzem seus pontos de venda são "esquemas operacionais que devem ser compreendidos em si [...] e não como meras derivações de racionalidades individuais" ${ }^{\prime \prime 3}$. Cada ato de produção do espaço da venda, nesse sentido, constitui um modo de fazer aprendido cotidianamente, ao invés da solução óbvia à necessidade de montar um ponto de venda. Isso fica claro no registro de campo abaixo, em que é descrito o procedimento de montagem de uma das opções senegalesas de espaços de venda:

O primeiro momento com Maba foi marcado por essa conversa sobre a qualidade de meu francês, mas isso não foi o relevante: paralelamente, ajudei-o a construir o local de venda, a partir de demanda sua. "Segura ali, cara...", foi o que disse quando teve maior dificuldade em domar a lona sobre a qual colocaria os tênis, em vistas do forte vento gelado que batia sobre nós (e que continuaria a fazê-lo ao longo do período em que

\footnotetext{
${ }^{27}$ PINTO, Matheus Rosa. As metamorfoses do trabalho urbano: o caso dos comerciantes informais de Santa Maria - RS (1980-2011). [Dissertação de Mestrado em História], Universidade Federal de Santa Maria, 2015.

${ }^{28}$ GOFFMAN, op. cit., p. 117.

${ }^{29}$ DE CERTEAU, Michel. The practice of everyday life, p. XII-XIII.

30 VEDANA, Viviane. Técnicas corporais e ritmos de trabalho nos mercados de rua: um ensaio sobre a relação entre gestos e atos de fala, p. 40.
} 
estive ali). Logo me prontifiquei e segurei com um pé uma das pontas do material e, com uma das mãos, a outra. Assim, segurei o tecido no chão para que o senegalês pudesse colocar os tênis. Primeiro, tirou de uma sacola preta que pegou de sua mochila todos os itens a serem dispostos, jogando-os sobre a lona como forma de mantê-la estável para a arrumação seguinte. Em seguida, com meu apoio do outro lado, pôde ir arrumando os tênis sob minha observação [...]. Seu manuseio seguia um padrão: identificava quais eram os pares e, em seguida, dispunha um tênis sobre o outro, sendo o primeiro apontado para a frente do ponto de venda e o segundo colocado em cima, formando um ângulo de 90 graus com seu par, de modo que o maior número possível de partes de cada conjunto de calçados fosse visível mesmo ao mais desavisado dos olhares. A certa altura, estava a emular essa arrumação de Maba e pareço ter me saído bem, apesar da insegurança, posto que o senegalês não manipulou os pares que dispus: a estratégia é que me pareceu interessante, já que, pensando agora, eu provavelmente faria a exposição com cada calçado ao lado de seu par, inviabilizando a maior facilidade de visualização dos produtos com a qual Maba mostrava trabalhar naquele momento (Diário de campo, 10/05/2017).

Como brevemente mencionado, a vestimenta utilizada pelos senegaleses em sua venda de rua é um segundo elemento constituinte dos espaços de venda que produzem em Santa Maria: além dos produtos, as roupas desses vendedores captam a atenção dos transeuntes. São pontos de visibilização da atividade senegalesa no cotidiano de quem passa pelos trechos de calçada comumente ocupados pelos imigrantes ${ }^{31}$. Várias situações de campo atestaram que, com certa frequência, os clientes desses vendedores têm consciência da ligação entre um e outro ponto de venda: sabem que são pessoas de origem semelhante, que vendem determinado conjunto de produtos e que trabalham na calçada de forma similar. Uma instância empírica marcante nesse sentido emergiu de uma conversa com Ahmadou. Relatando que comprara todas as suas peças de roupa pessoais de Maodo (outro senegalês estabelecido há mais tempo em Santa Maria e já dono de uma pequena loja formalizada), disse que o uso pelo vendedor do mesmo vestuário exposto para venda é importante tanto para fins de propaganda quanto para o reconhecimento público dos pontos comerciais senegaleses e sua relação (Diário de campo, 08/07/2017). A seguir, duas das fotografias feitas em trabalho de campo exemplificam os espaços de venda senegaleses conforme formados pela organização dos produtos e pela vestimenta usada por quem vende.

O que querem dizer os senegaleses de Santa Maria com essa prática de vestuário na venda de rua? Se, como mencionado, pretendem-se profissionais em sua relação com os produtos (ao invés de artistas), então as roupas que

${ }_{31}$ MAGNANI, José Guilherme Cantor. Quando o campo é a cidade: fazendo antropologia na metrópole, p. 18. 
utilizam para trabalhar servem de algum modo ao mesmo papel social. Como no caso da disposição dos produtos e da relação corporal com estes, a estética pretendida por esses imigrantes vendedores por meio das roupas de trabalho que usam tem caráter relacional. Para os senegaleses de Santa Maria, percebeu-se em campo que se vestir bem é se mostrar digno de respeito e confiança nas relações comerciais. Trata-se de um atestado moral, pela via da imagem, sobre o vendedor e a forma como desempenha a venda. Para esses senegaleses, vestir-se da forma como se vestem é demonstrar ao cliente médio que estar em seu espaço de venda é aceitável e normal, tratando-se de uma transação de bens como qualquer outra.

\section{Foto 1 - Cheikh e seu ponto de venda na opção mais portátil}

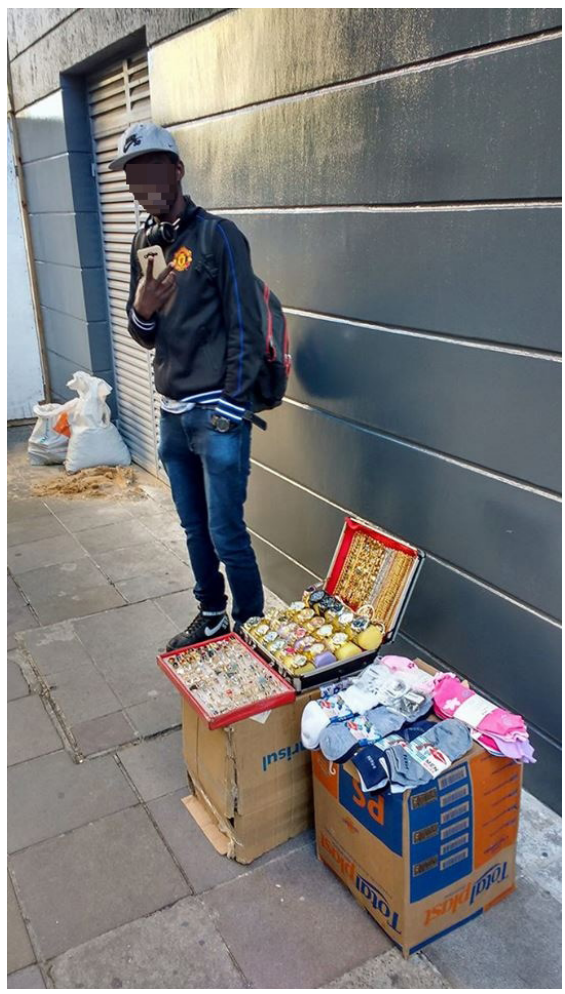

Foto 2 - Maba e seu ponto de venda na opção mais completa

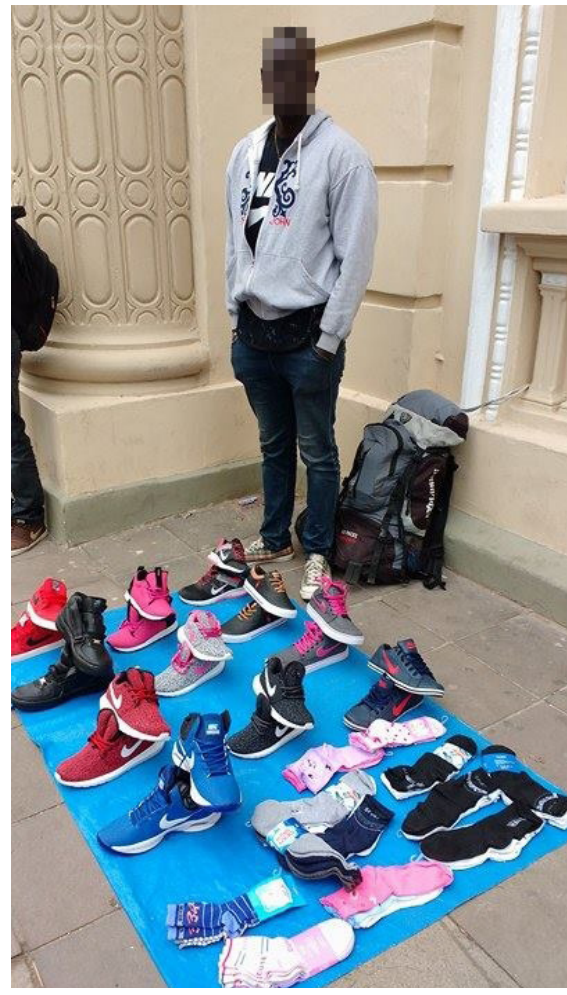

Fonte: arquivo pessoal.

Em campo, percebeu-se que isso era resultante da interpretação que esses imigrantes faziam das percepções estéticas circulantes entre outros vendedores de rua e a clientela. Mais uma vez, o caso dos artesãos hippies se mostra representativo para a compreensão do que é "se vestir para trabalhar", segundo os senegaleses 
de Santa Maria. A pesquisa etnográfica realizada por Bruna lung ${ }^{32}$ com tais artesãos da cidade fornece dados dos quais se pode partir. A autora demonstra que a clientela frequentadora dos pontos de venda próximos aos ocupados pelos hippies comumente expressava, nas interações de suas compras, um discurso negativo acerca desses artesãos: "sujos" e "preguiçosos" eram adjetivos que ouvia com frequência em seu trabalho de campo. Ao estarem regularmente a poucos metros de distância dos artesãos hippies e tendo em vista que, na calçada, "a única extensão do outro é frequentemente a do olhar"33, notou-se que os senegaleses de Santa Maria se apropriam desse discurso público como meio de diferenciação. Enquanto os artesãos se vestem para afirmar determinado estilo de vida que está em sintonia com os produtos que criam e vendem (às vezes narrando aos clientes histórias de aventura, liberdade e arte), os senegaleses parecem se vestir estritamente para vender produtos dos quais, como já se afirmou, são apenas mediadores. Por meio de uma aparência menos exótica ao público geral, com roupas similares às utilizadas no dia a dia por jovens brasileiros de diferentes classes (como demonstram as fotos há pouco expostas), alcançam uma variedade maior de clientes e se representam como profissionais do comércio de rua.

Desse ponto de vista, ao contrário do que ocorre com os artesãos hippies, o esforço dos senegaleses em termos de causar boa impressão pela vestimenta se dá dentro dos limites daquilo que percebem estar "no gosto do povo". É pelas roupas que é possível, assim, notar um processo situacional de diferenciação interétnica: interpretando uma relação de poder comum no contexto social de seu trabalho, os senegaleses se apropriam de uma noção do que é se vestir para vender na rua que, então, é expressa pelas vestes utilizadas. Trata-se, assim, da dimensão ideológica de uma identidade étnica enquanto um valor que presume um grau de consciência e escolha ${ }^{34}$. Em se falando do papel social de vendedor de rua, os senegaleses afirmam uma diferença cultural em relação aos artesãos hippies que é objetificada na vestimenta:

Conversei com Ahmadou aos poucos, notando [...] que estava muito concentrado no fluxo de pessoas: logo pensei se não estaria atrapalhando, já que o acordo era o de ficar com Maba e não com ele, então fiquei calado na maior parte do tempo. O mais relevante foi que, ao falarmos primeiro sobre a música do homem que toca sempre do outro lado da rua, chegamos no assunto do possível amigo de Cheikh, que não vendia ali nesse dia, mas que comentei comumente ocupar aquele espaço também. Mencionei que colocava Bob Marley, e que era melhor que a música que escutávamos no momento, mas Ahmadou disse que ele era "vagabundo". Indaguei o porquê, ao que disse

\footnotetext{
32 IUNG, Bruna Pinheiro. O universo dos "malucos-beleza": um estudo antropológico sobre arte, sobrevivência e estilo de vida dos artesãos da Praça Saldanha Marinho, em Santa Maria. Monografia [Graduação em Ciências Sociais], Universidade Federal de Santa Maria, 2007.

${ }^{33}$ LE BRETON, op. cit., p. 78.

${ }^{34}$ CARDOSO DE OLIVEIRA, Roberto. Identidade, etnia e estrutura social.
} 
que não se vestia direito, que não se cuidava, dando a entender que dormia na rua: "tem que colocar uma roupa boa... [gestos movendo as mãos para cima e para baixo indicando sua vestimenta]". Insisti, mencionando um "mas e do Cheikh, ele não é amigo será?", ao que respondeu algo como "do Cheikh não sei, mas meu não é...". O ponto era o de que as impressões de Ahmadou em relação ao homem não eram nada boas, e a lógica argumentativa de seu julgamento era majoritariamente estética, me parece. Percebendo isso, destaquei: "ah, tem que estar bonito pra vender, se arrumar direitinho, estar bem...", recebendo dele um "isso, é muito importante..." (Diário de campo, 10/05/2017, Ahmadou diferencia suas roupas de venda das utilizadas por um artesão hippie que frequentemente ocupava um ponto de venda próximo).

Entretanto, seguindo Geertz ${ }^{35}$, pode-se esperar que o ponto de vista acima exposto pelo senegalês seja representativo apenas de uma possibilidade dentro de uma série de situações do mencionado contato interétnico. Não se trata, frisamos, de fronteiras simbólicas autossuficientes, mas, sim, ligadas às interações específicas que, variavelmente, as põe em evidência. É nesse sentido que se nota, aqui, o convívio entre cooperação e diferenciação na representativa relação entre senegaleses e artesãos hippies. Vale destacar uma situação específica. Nela, Ahmadou e Maba desmontavam seus pontos de venda, relatando rapidamente que haviam detectado a aproximação de um agente da fiscalização municipal. Inquietos enquanto verificavam se a apreensão seria tentada, começaram a conversar apressadamente sobre o fato com um artesão hippie que, na ocasião, estava próximo. De início, disse prontamente o artesão ao senegalês, referindo-se ao fiscal passante: "Não, mas eu conheço ele, ele mora no Bairro X [bairro de Santa Maria localizado longe do centro onde se dá a maior parte do comércio de rua], tá indo pra casa já, não tá trabalhando... não vai pegar vocês aí...". Em seguida, com os senegaleses de volta a seus pontos de venda e já calmos, o autor presente em campo perguntou ao artesão se suas mercadorias não eram apreendidas pelos fiscais, ao que respondeu, vangloriando-se: "não, é artesanato né?!" (Diário de campo, 28/06/2017). Virou-se de costas, encerrando o assunto e se retirando com um sorriso orgulhoso e um tanto debochado. Sabendo que a legislação municipal permite a venda de rua de produtos artesanais, o indivíduo implicitamente ridicularizava a situação do grupo de vendedores que acabara de ajudar. Em síntese, diferentes situações interacionais expressam diferentes dimensões de uma mesma fronteira interétnica. Envolvido nela, o fazer cotidiano de espaços de venda de rua pelos imigrantes senegaleses de Santa Maria os mantém, ao mesmo tempo, aprendizes e produtores das calçadas que ocupam.

\section{Considerações finais}

Neste artigo, analisamos a produção dos espaços da venda de rua desempenhada por imigrantes senegaleses estabelecidos na cidade de Santa

${ }^{35}$ GEERTZ, Clifford. O saber local: novos ensaios em antropologia interpretativa, p. 106. 
Maria. Por meio do observado em trabalho de campo, isso implicou tratar tanto a vestimenta dos vendedores quanto seus produtos como elementos constituintes de um espaço socialmente relevante em dois sentidos: (i) emerge por meio de um aprendizado dialógico que os senegaleses estabelecem em seu cotidiano de interações com outros vendedores de rua e que está ligado à condição de imigrantes desses indivíduos; (ii) tem efeitos conscientes nas interações com a clientela, gerando nessa impressões positivas em comparação a outros espaços de venda. Situado em uma experiência social de demandas simbólicas, o imigrante senegalês em Santa Maria é levado a absorver tudo o que pode enquanto trabalha: interpretando o que é ser vendedor de rua no contexto cultural em que habita, desenvolve suas próprias práticas corporais, dentre as quais as que lidam com o espaço.

Em outras palavras, os senegaleses em questão gradualmente constroem uma agência autêntica sobre o espaço, no sentido de que diferenciam seus pontos de venda dos de outros vendedores (conforme nos revela o caso representativo de sua relação com os artesãos hippies) e, paralelamente, constituem seu trabalho como um fazer cotidiano que se apropria discretamente das calçadas (como segmentos urbanos oficialmente planejados para fluxos incessantes em direção ao comércio formal). Os pontos de venda dos senegaleses de Santa Maria constituem, então, de "espaços" segundo a definição elaborada por de Certeau ${ }^{36}$. Enquanto "um lugar é [...] uma configuração instantânea de posições", implicando "uma indicação de estabilidade", o espaço "ocorre como o efeito produzido pelas operações que o orientam, o situam, o temporalizam, e o fazem funcionar em uma unidade polivalente de programas conflituosos ou proximidades contratuais". Ao contrário das lojas do comércio formal e das zonas de perigo criadas pela ação da fiscalização municipal, os espaços senegaleses de venda, como os espaços dos outros vendedores, têm uma existência fluída: cada situação é também uma condição de sua possibilidade, sendo essa, por sua vez, sempre relacional. É desse modo que esses imigrantes ocupam as calçadas de Santa Maria: configurando não um lugar, mas um espaço cujo fazer cotidiano os transforma em personagens reconhecíveis no comércio de rua da cidade.

\section{Referências bibliográficas}

CARDOSO DE OLIVEIRA, Roberto. Identidade, etnia e estrutura social. São Paulo: Pioneira, 1976.

DE CERTEAU, Michel. The practice of everyday life. Los Angeles: University of California Press, 1984.

DE CÉSARO, Filipe; BARBOSA, Lorena Salete; ZANINI, Maria Catarina. Um panorama das migrações internacionais para o sul do Brasil: haitianos e senegaleses em movimento. In ZIMERMAN, Artur (org.). Impacto dos fluxos imigratórios recentes

${ }^{36}$ DE CERTEAU, op. cit., p. 117. 
no Brasil. Santo André: Editora da UFABC, 2017, p. 80-101.

DE CÉSARO, Filipe; ZANINI, Maria Catarina. Migração senegalesa e mouridismo: um breve exercício interpretativo. In TEDESCO, João Carlos; KLEIDERMACHER, Gisele (orgs.). A imigração senegalesa no Brasil e na Argentina: múltiplos olhares. Porto Alegre: EST Edições, 2017, p. 255-274.

FOURON, Georges; GLICK-SCHILLER, Nina. Laços de sangue: os fundamentos raciais do Estado-nação transnacional. Revista Crítica de Ciências Sociais, v. 1, n. 48, 1997, p. 33-66.

GEERTZ, Clifford. A interpretação das culturas. Rio de Janeiro: LTC, 1989.

GEERTZ, Clifford. O saber local: novos ensaios em antropologia interpretativa. Petrópolis: Vozes, 1997.

GLICK-SCHILLER, Nina; LEVITT, Peggy. Conceptualizing simultaneity: a transnational social field perspective on society. IMR, v. 38, n. 3, 2004, p. 1002-1039.

GOFFMAN, Erving. A representação do eu na vida cotidiana. Petrópolis: Vozes, 1985. HARTMANN, Luciana. Performance e experiência nas narrativas orais da fronteira entre Argentina, Brasil e Uruguai. Horizontes Antropológicos, v. 11, n. 24, 2005, p. 125-153.

LE BRETON, David. A sociologia do corpo. Rio de Janeiro: Vozes, 2007.

MAGNANI, José Guilherme Cantor. Quando o campo é a cidade: fazendo antropologia na metrópole. In MAGNANI, José Guilherme Cantor; TORRES, Lilian de Lucca. Na Metrópole - Textos de Antropologia Urbana. São Paulo: Edusp, 1996, p. 1-30.

MAUSS, Marcel. As técnicas do corpo. In IDEM. Sociologia e Antropologia. São Paulo: EPU, 2014.

SAYAD, Abdelmalek. A imigração ou os paradoxos da alteridade. São Paulo: EDUSP, 1998. VEDANA, Viviane. Técnicas corporais e ritmos de trabalho nos mercados de rua: um ensaio sobre a relação entre gestos e atos de fala. In ZANINI, Maria Catarina Chitolina; SANTOS, Miriam de Oliveira. Feiras, feirinhas e feirões: a "economia" dos centavos em foco. São Leopoldo: Oikos, 2017, p. 40-59.

VERTOVEC, Steven. Transnationalism. London: Routledge, 2009.

Recebido para publicação em 29.01.2018

Aceito para publicação em 22.02.2018

Received for publication in January 29 2018 Accepted for publication in February $22^{\text {th }}, 2018$

ISSN impresso 1980-8585

ISSN eletrônico 2237-9843

http://dx.doi.org/10.1590/1980-85852503880005206 